\title{
Contos de fadas: um diálogo pelas vias da Arte
}

\section{Entrevista com Katia Canton}

Fairytales: a dialogue through art

Interview with Katia Canton

$\underline{\underline{\text { Regina Célia Ruiz }}}$

1 Doutoranda em Estudos Comparados de Literaturas de Língua Portuguesa, área de Literatura Infantil e Juvenil - Universidade de São Paulo (USP). E-mail: reginaceliaruiz@gmail.com. 
Katia Canton é artista visual, escritora, jornalista, professora, curadora e crítica de artes. Estudou arquitetura, dança e formou-se jornalista pela ECA-USP, em São Paulo. Também estudou literatura e civilização francesas no curso de estudos superiores dado pela Aliança Francesa juntamente com a Universidade de Nancy II. Em 1984, transferiu-se para Paris, com uma bolsa de estudos de dança moderna no estúdio Peter Goss.

Viveu em Nova York por oito anos, onde trabalhou como repórter para vários jornais e revistas, realizou Mestrado em Performance Studies, pela Tisch School of the Arts, New York University, com o título Dança e Performance Pós-Moderno (Kinematic and The New Performance), e Doutorado em Artes Interdisciplinares pela Faculdade de Artes Visuais e Educação, da New York University, com a tese The Fairy Tale revisited an interdisciplinary approach to the Arts. Sua livre-docência, em Teoria e Crítica de Artes, pela ECA-USP, Autorretrato, Espelho de Artista, revela as potências da arte na educação.

A pesquisa acadêmica de Katia Canton é interdisciplinar, relaciona as artes e os contos de fadas de várias épocas e culturas do mundo. Trabalhou um ano e meio como bolsista no MoMA, de Nova York, criando projetos de arte e narrativa no Departamento de Educação. De volta ao Brasil, ingressou como docente na Universidade de São Paulo, sendo professora associada e curadora do Museu de Arte Contemporânea (onde foi vice-diretora) durante 28 anos. Atualmente, é docente do programa de Pós-graduação Interunidades em Estética e História da Arte.

Seu trabalho artístico é multimídia, incluindo desenho, pintura, fotografia, objetos e, conceitualmente, relaciona-se a questões sobre sonhos, desejos e narrativas. Tem realizado exposições em museus, galerias e instituições culturais no Brasil e no exterior, desde 2008.

Como autora, além de escrever livros sobre arte, criou mais de 50 livros ilustrados sobre contos de fadas para o público infantil e juvenil, sendo várias vezes premiada no Brasil e no exterior. Entre elas, recebeu, por três vezes, o prêmio Jabuti e outras premiações da Fundação Nacional do Livro Infantil e Juvenil. ${ }^{2}$

Katia Canton nos concedeu esta entrevista, por e-mail, em 28 de setembro

2 Parte da biografia de Katia Canton foi retirada de https://katiacanton.com.br/bio/. Acesso em: 18 set. 2020. 
de 2020, nos permitindo conhecer melhor seus trabalhos, projetos e, sobretudo, sua pesquisa e encantamento pelos contos de fadas.

I. Antes de iniciarmos, quero agradecer a sua participação nesta $12^{a}$ Edição da Revista Literartes. É uma honra podermos conversar sobre um tema que tanto nos desafia e interessa, uma tradição literária tão profícua que extrapolou os limites dos suportes literários impressos e se mantém viva na nossa memória coletiva até os dias de hoje. A minha primeira pergunta retoma a sua formação acadêmica voltada a múltiplas linguagens. É notória a sua intensa versatilidade artística, transitando pela literatura, artes visuais, dança, poesia... Como toda a sua experiência nas artes converge para um trabalho com os contos de fadas?

Eu é que agradeço o carinho e o interesse pelo meu trabalho. Acho que os contos de fadas são a linha que perpassa, "amarra” e dá liga a tudo o que fiz e faço. Minha relação com essas histórias paradigmáticas data da minha infância. Quando menina, por conta de um problema de saúde e também de uma timidez muito grande, não era tanto de brincar na rua. Ficava muito em casa e costumava tocar a campainha do apartamento da minha tia avó Cecília, que morava no mesmo prédio, no bairro de Santa Cecília, região central de São Paulo. Ela era uma grande contadora de histórias e conhecia todos os contos de fadas. Eu ia lá e pedia a ela as histórias clássicas. Depois, ia para o espelho e estranhava...atestava a impossibilidade de ser como aquelas princesas europeias, loiras, lindas, lânguidas. Esse foi um primeiro grande nó entre desejo e falta. A arte sempre fez parte da vida. Venho de uma família que me proporcionou esse tipo de formação. $\mathrm{Na}$ faculdade, desisti da arquitetura, ainda que adorasse desenhar, e me dediquei totalmente à escrita e à dança. Durante o curso de jornalismo, na ECA-USP, fiz também o Nancy, que era uma especialização em Literatura e Civilização Francesa dada em parceria pela Aliança Francesa 
e a Universidade de Nancy II. Ali ganhei uma bolsa para fazer dança e estudar artes cênicas no Studio Peter Goss, em Paris, em 1984. Escrevi muito nesse período. Daí retornei, terminei a faculdade e fui para Nova York. Também tive bolsa durante toda a formação acadêmica, o mestrado e o doutorado na Universidade de Nova York. Performance Studies era uma modalidade nova, que combinava as artes cênicas com antropologia e sociologia. No momento de escolher um tema para a pesquisa da dissertação, minha tia Cecília me veio imediatamente à mente. Escolhi trabalhar com os contos de fadas. Queria entender como escritores e artistas contemporâneos tratavam o tema e modificavam seus sentidos. Acho que queria me entender também!

Durante o doutorado, a mesma pesquisa se ampliou. Estudei coreógrafas e artistas contemporâneas, como Maguy Marin, Pina Bausch e o grupo feminino Kinematic, mas também as origens dos contos, seus aspectos de oralidade e comunicação, sua implicação na construção cultural de determinadas sociedades, sobretudo no que concerne à educação da mulher e das crianças. Continuo apaixonada pelo tema e, cada vez mais, me aprofundo na produção contemporânea em várias mídias, seja na literatura, nas artes visuais, na performance, na poesia, no cinema e até na publicidade. Vejo as formas de representação dos contos de fadas como índices culturais importantes para falar sobre quem somos e como nos vemos.

O ser bumano é, por princípio, um animal contador de bistórias. Há um aspecto universal que sustenta a existência e permanência das histórias no decorrer da existência da humanidade e também um aspecto mutável, um jeito singular de recontar ou reescrever uma mesma história.

2. Você realiza uma importante pesquisa sobre o papel da mulher nos contos de fadas. É diretora artística do Museu Internacional da Mulher (MIMA), em Lisboa, o primeiro museu internacional dedicado à arte contemporânea, ao artesanato e a movimentos sociais de mulheres. Em novembro de 20I9, você inaugurou a primeira exposição desse museu: 
Meu Corpo, minba Língua, com foco na violência contra a mulher, no corpo e na lusofonia da língua portuguesa. Pensando nesse olhar afinado para o protagonismo feminino, gostaria que você nos contasse um pouco sobre como surgiu a ideia de se criar esse museu, que reúne vozes e imagens em torno da mulher e como todo esse projeto dialoga com a sua pesquisa sobre contos de fadas.

$\mathrm{Na}$ verdade, foi justamente a minha pesquisa sobre o feminino e os contos de fadas que levou ao convite para ser a diretora artística do MIMA (Museu Internacional da Mulher, Associação). O convite veio por parte de Paula Castelar, jornalista portuguesa que é a presidente da associação. Eu estava exibindo uma mostra de desenhos e pinturas sobre o assunto na galeria e fiz uma palestra, ambas na Faculdade de Letras da Universidade de Lisboa. Já tinha uma experiência ampla com museus, pois, desde o doutorado, havia trabalhado no departamento de arte-educação do MoMA (Museu de Arte Moderna de Nova York) e, desde o final de 1993, estive no MAC-USP (Museu de Arte Contemporânea da USP), como docente e curadora, além de ter sido vice-diretora e diretora em exercício. O propósito do MIMA é ser um museu vivo, de representatividade da mulher lusófona, espalhada pelo mundo.

Há uma história muito rica e interessante por trás da construção dos contos de fadas. E nela há uma narrativa que refaz o próprio percurso do lugar ocupado pela mulher na sociedade, desde os primórdios, na tradição oral quando se ouviam as vozes do povo, passando pela apropriação das histórias por uma elite barroca europeia e, mais tarde, pela sociedade patriarcal norte-americana de Walt Disney. E, é claro, há as versões contemporâneas que colocam muito dessas versões em cheque.

No Dia 25 de novembro de 2019, inauguramos a primeira exposição do museu, Meu Corpo, Minha Língua, com foco na violência contra a mulher, no corpo e na lusofonia. A exposição contou com sete artistas, entre eles seis mulheres e um homem que tratava de questões do feminino. As produções 
vieram de Portugal, Brasil, Moçambique, Angola e Macau. O que nos unia era a soberania sobre o território do corpo e da língua portuguesa. A exposição foi realizada no Fórum Grandela, um pequeno palacete muito lindo, que é a Casa da Cidadania da Junta de São Domingos de Benfica. Fizemos uma parceria com a vereadora local, Cristina Valério, que emprestou o espaço e ajudou a cuidar da produção. Temos mais outras duas mostras praticamente prontas. Uma delas seria produzida esse ano, mas com a Covid deixamos tudo para 2021. Da questão da soberania feminina sobre seu corpo, passaremos a abordar a necessidade de narrativas femininas para se recontar a história do mundo. E isso implica uma forma de lidar com o mundo que seja mais sustentável, mais horizontalizada. Vamos trabalhar com novas versões dos contos da humanidade, que são versões contemporâneas, transdisciplinares, pós-patriarcais.

3. Quando se fala em contos de fadas, para um número considerável de pessoas, o que vem à mente são as narrativas mais conhecidas, publicadas por Charles Perrault e Irmãos Grimm, que se popularizaram ainda mais nas versões Disney. Sabemos que esses contos tiveram início na oralidade, o que dificulta precisarmos suas reais origens, mas, há um grupo de mulheres, deixadas à margem de muitas análises e pesquisas, que foram fundamentais para a criação e disseminação desses contos. Refiro-me às autoras francesas que organizavam o Salão das Preciosas (século XVII). Uma das integrantes desse salão era a Madame d'Aulnoy que entrou para a história da literatura por produzir o primeiro conto de fadas literário de que temos notícia "A Ilha da Felicidade" e deixou uma grande marca ao cunhar o termo contos de fadas. Como você percebe esse movimento, de, em pleno século XXI, o papel das mulheres na autoria e disseminação desses contos tradicionais ainda não ser devidamente reconhecido? 
É muito interessante como tudo tem vindo à tona nesse período da história. Na literatura estamos hoje discutindo a produção feminina. Nas artes visuais, descobrimos que, desde o século XVI e XVII, existiram pintoras maravilhosas que não apareciam. A produção das mulheres, dos afrodescendentes, dos indígenas, enfim, há tantas produções a serem redescobertas e comentadas. O mundo e a cultura não foram construídos apenas pelo homem branco europeu. Isso é um reducionismo ligado à permanência de poder do patriarcado, que agora começa a ser ampliado.

Especificamente na literatura que inaugura o conto de fadas como gênero, a movimentação das mulheres foi primordial. Sempre insisti nisso. Não podemos esquecer que aquilo a que chamamos conto de fadas é, necessariamente, um produto literário, datado justamente desse período do século XVII. Minha primeira coleção de contos de fadas com artistas, chamada Arte Conta Histórias, de 1997, contém um livro chamado Conversa de Madame, que aborda um pouco do clima dos salões da corte francesa sob Luís XIV, particularmente em Versailles, onde a moda dos contos de fadas foi instituída pelas mulheres. Durante à noite, as histórias que eram ouvidas dos empregados durante o dia ou ainda inventadas eram transformadas, tratadas com maneiras barrocas e escritas no formato conto de fadas.

Esse termo foi inventado por uma das madames, uma condessa chamada Madame Marie-Catherine d'Aulnoy, utilizando simbolicamente a imagem das fadas, seres encantados e diminutos, de origem celta, justamente para falar de histórias de magia e encantamento, que eram tratadas com refinamento, ao estilo barroco do final do século XVII. O termo ficou e nos acompanha até hoje.

É curioso saber que Madame d'Aulnoy nunca viveu um "conto de fadas" ou foi "feliz para sempre". Casou-se aos 15 anos com um homem trinta anos mais velho, provavelmente um homem abusivo. Participou de uma conspiração para tentar matar o marido, fugiu, provavelmente virou espiã. Depois voltou à França e publicou uma dezena de livros e vários contos de fadas. 
4. Outra questão que nos chama a atenção quando estudamos o percurso dos contos de fadas é a censura. Essas narrativas eram, originalmente, direcionadas para o público adulto e sofreram muitas adaptações para que pudessem ser inseridas no universo infantil e juvenil. Atualmente, existem movimentos que se opõem aos contos de fadas, pois defendem que essas histórias ratificam o estereótipo da mulher submissa, contrariando a liberdade e autonomia feminina. Gostaria que você falasse um pouco sobre as transformações sofridas pelos contos e sobre esse momento crítico que censura esse gênero até os dias de hoje.

Acho que a questão principal ligada à formatação dos contos de fadas tal como a indústria Disney a coloca tem mais a ver com o capitalismo, desde seu formato mercantilista, do que com a censura por si só. A “adequação” dos contos de fadas para o público infantil surgiu em um momento histórico denominado como "a era da descoberta da infância”. As crianças passaram a ser vistas, no século XVIII, como um público com potencial de consumo. E para ela foram criados produtos próprios, vinculados à proteção e à educação. Seguindo esse pensamento percebemos como os contos de fadas, sobretudo aqueles de Charles Perrault, serviram bem ao propósito.

Ele buscou adaptar as histórias - ainda que contos pontuados por erotismo - para as crianças. Quando assumiu a autoria das histórias (inicialmente, atribuiu a autoria ao filho e usou sempre a personagem da "Mamãe Gansa") atribuiu seu cuidado na edição do conteúdo ao fato de ser um pai de quatro filhos, órfãos de mãe. Lapidou as narrativas de forma a se tornarem uma espécie de cartilhas de boa educação e conduta. Sobretudo para as meninas. E então criou as moralités ou moralidades, pequenos poemas ao final de cada conto, com uma mensagem clara sobre condutas. Por exemplo, as 
meninas deveriam ser doces e suaves, como a Cinderela, que caminha e até dança com um sapato de cristal sem rachá-lo; deveriam ter paciência, como é o caso de "A Bela Adormecida", que dorme por 100 anos, aguardando seu príncipe; deveriam ser obedientes, ao contrário de Chapeuzinho Vermelho, que tomou o caminho errado e foi engolida pelo Lobo.

Sabemos que, até esse momento histórico, os contos não eram pensados para crianças. Porque nem mesmo se pensava na singularidade da criança.

5. Ainda pensando nas novas versões de contos de fadas, muitos têm sido reescritos e adaptados para as artes visuais, para o teatro, cinema e musicais. Qual o seu olhar para essas adaptações?

Meu olhar é sempre curioso. Sou jornalista e artista, quero entender como essas novas adaptações querem dizer algo a respeito de quem somos e para onde queremos ir. Há muitas considerações sobre essas novas versões, sobretudo aquelas que hoje perseguem versões politicamente corretas. Essa questão é complexa e dá um verdadeiro tratado!

6. No período de março a agosto deste ano, o Museu Nacional de História Natural e da Ciência, de Lisboa, recebeu a sua exposição Inventários de Cura, um projeto relacionado com a sua investigação sobre medicamentos e tinturas, com foco nas necessidades humanas de afeto e acolhimento. Como esse projeto dialoga com sua pesquisa sobre contos de fadas?

O acaso acabou tenho um papel importante nesse percurso. Minha exposição no Museu de História Natural foi realizada dentro de um antigo laboratório de química. Meu desejo com a mostra é falar de cura. Cura alquímica. Cura para a humanidade, pensando de forma múltipla na busca de apoio mútuo, equanimidade, justiça. A questão de gênero entra muito nessa 
realidade. Precisa ser curada. Acho que todos sabem o quanto a pandemia fez aumentar a violência contra a mulher. A disparidade entre os gêneros ainda é imensa.

7. Na última edição da Revista Literartes, Jack Zipes concedeu uma entrevista e, em resposta a um questionamento sobre protagonismo feminino disse que... "há uma tendência atual e muito bem-vinda de centenas de jovens escritores e artistas de todos os países do mundo que estão explorando o gênero conto de fadas para expressar, para dar voz às esperanças de minorias de todos os tipos. $\mathrm{O}$ perigo sempre é a indústria cultural - os editores e produtores de filmes que simplesmente procuram fazer dinheiro com as políticas da moda do momento. Uma das mais maravilhosas qualidades de todos os seres humanos, no entanto, é o nosso desejo de trabalharmos juntos e de ajudarmos uns aos outros a cultivar um mundo em que todos sejam tratados com gentileza e compaixão. Nosso maior problema vem das elites de todas as sociedades que iniciam criminosas guerras ideológicas”. Você poderia comentar essa afirmação de Jack Zipes?

Adoro essa generosidade de olhar. Tive a chance de conhecer pessoalmente Jack Zipes e participar de vários encontros acadêmicos com ele durante o período em que vivi nos Estados Unidos. Ele é um grande humanista. E segue uma pesquisa de viés marxista, olhando para o percurso das histórias a partir do ser humano e da luta pela igualdade social. Zipes, aqui, fala do que há de mais profundo e central nessas narrativas: o desejo de esperança por um mundo melhor. Essa é verdadeiramente a essência, daí as múltiplas facetas de ajudas mágicas para tanto. O resto — os enredos e visões que se modificam no tempo e no espaço — são as construções culturais que nos singularizam. 


\section{O que você pode nos contar sobre as suas próximas publicações ou} exposições? Há algo já sendo preparado na linha de contos de fadas?

Sim, sempre! Esse é o trabalho da minha vida. Lancei durante a pandemia dois novos livros, Meninas Incríveis, pela Carochinha e A Princesa que Mora no Livro, pela editora da Estrela Cultural. Meninas Incríveis reconta três contos muito antigos sobre a transformação de protagonistas fortes, que redesenham suas vidas. A Princesa que Mora no Livro conta a história de uma princesinha entediada, que mora dentro de um livro luxuoso, mas não consegue usufruir dele, simplesmente porque não sabe ler. Lá pelo meio das páginas encontra um sábio, que não apenas lhe ensina a ler, mas conta para ela a história do livro e o desejo humano de criar a escrita. Daqui a pouco lanço outro, que ainda não tem nome. Quanto às artes visuais, no dia 8 de março de 2021, dia Internacional da Mulher, vou fazer uma exposição em Lisboa sobre Lugares de Encantamento. Será no mesmo Fórum Grandela, onde foi a primeira coletiva do MIMA.

\section{Para finalizar, pensando em tantas leituras, análises e pesquisas que} você realiza e já realizou, existe um conto em especial que trouxe a você alguma provocação ou que tem acompanhado a sua trajetória?

Acho que sou filha de Cinderela. Faz parte da minha geração questionar o mito da mocinha que espera a chegada de um príncipe para salvá-la. No início da época de faculdade li O Complexo de Cinderela, livro escrito em 1981 por uma autora chamada Collette Dowling, que falava do medo e a insegurança da mulher em relação à sua própria independência. Acho que essa leitura foi impactante nos meus questionamentos sobre o papel da mulher nas histórias. Cinderela é, provavelmente, o conto de fadas mais popular de toda a história, com mais de 490 versões já catalogadas e estudadas. Há posicionamentos do feminino que são muito diversos no enredo das narrativas 
contadas ou escritas ao longo do tempo, desde a China antiga até os dias de hoje. E é aí que o conto de fadas se transforma num testemunho cultural importantíssimo, pois trata-se de uma construção literária, artística, mas também de um documento civilizatório, que testemunha como as relações sociais se estabelecem em determinado contexto histórico. 